\title{
MOA-S: A SCENARIO MODEL FOR INTEGRATING WORK ORGANIZATION ASPECTS INTO THE DESIGN PROCESS OF CSCW SYSTEMS
}

\author{
Kerstin Grundén \\ University of Borås \\ Sweden
}

\begin{abstract}
Scenarios using the MOA-S model are proposed as a method for discussion and design of the future work organization of CSCW systems. CSCW technology has the potential to enable design of the organization with more flexible communication patterns than previously available. However, we still lack methods for the design process of CSCW systems. A case study is presented of the development and test of a prototype in Lotus Notes for dealing with social insurance matters within the Swedish Social Insurance Board. The results of the case study are structured in accordance with the MOA-S model. The MOA-S model could then be used as a design tool in order to initiate and support a dialogue about the remaining design of the work organization in the CSCW system.
\end{abstract}

Keywords: CSCW, Lotus Notes, social insurance board, work organisation, work situation, efficiency, quality, systems development work, scenarios 


\section{Introduction}

The research field of computer supported cooperative work (CSCW) is a rather mature and broad research field with a history of more than 10 years. The focus of this research field on cooperative work among the people is taken as the departure point for an analysis of the design of CSCW technology support. The field of CSCW includes technology such as video communication, mainly supporting informal communication, as well as complex administrative systems for more formal communication, allowing communication regardless of time or geographical location. There is a lack of detailed empirical studies of consequences for the work processes when CSCW technology is used (Bannon and Schmidt 1995, p. 13). There is also a lack of design methods for CSCW systems. The traditional life cycle model for system development work is not as relevant for the development of CSCW systems. Traditional system development work has a more rigid character; most of the detailed specifications of the system are done in the early stages of the process. Supporting cooperation and coordination with information technology shows characteristics that differ from traditional system information systems (Grudin 1994; Kyng 1991).

The design of CSCW systems could lead to more flexible communication patterns within the organization. New organizational ideals, often characterized as a paradigmatic change of organizational thinking, have emerged. These new organizational forms are characterized in the literature as boundless (Ashkenas 1997), flexible (NUTEK 1996), process-oriented, customer-oriented, and learning-orientated (Argyris and Schön 1996). Most of these taxonomies are, however, to some extent overlapping and no clear definitions exist (Andersen and Chatfield 1996). Many public sector organizations by tradition have a rather large, complex and bureaucratic structure. However, even in the public sector there are many efforts to restructure the organization and technology in order to achieve quality and efficiency gains. The central level of the Swedish social insurance board (SIB) has formulated a very large project, "Försäkringskassan 2005" (SIB 2005), including a vision of the future work. The development and test of the ELAKT prototype was part of this project. SIB 2005 also included many sub-projects within the following fields: analysis of the work activities, competence, technology, planning and control (Försäkringskassan 1998). The vision that was formulated for the project included a customer orientation, e.g., more flexible ways of interacting with the customer. ${ }^{1}$ The customer could execute some current work tasks, such as information through phone systems or Internet communication, with new functions for customer service. The use of the new technology also was expected to lead to a reduction of the time needed for dealing with social insurance matters. The technology was seen as the main work instrument. According to the vision, the organization should be less authoritarian than today, more process-orientated, and more of a learning organization (Jälmestål, Sköld, and Wahlqvist 1998).

The use of CSCW technology has the potential to facilitate the design of such an organization as it allows for a flexible structure of communications in the organization. The change of an organization from bureaucratic and hierarchical communication patterns toward increased flexibility means that the organizational culture needs to be changed as well. There is a need for design methods to facilitate such a process by facilitating

\footnotetext{
${ }^{1}$ Notice the fact that the concept "customer," rather than "client," is used in the vision of SIB 2005.
} 
discussions and dialogues of different organization alternatives within the CSCW system. In this article, scenarios using the MOA-S ${ }^{2}$ model see (Figure 1) are proposed as such a design method that especially focus on ways the work situation and efficiency and quality aspects could be affected by different design alternatives for the organization and the technology. MOA-S is used as a frame of analysis in a case study where the ELAKT prototype for electronically dealing with social pension matters was tested at a local office within the Social Insurance Board of Sweden. The model is also introduced to systems developers within the organization.

In the next section, the case study of the ELAKT prototype is briefly presented. The results of the study are structured according to the MOA-S model. This scenario is expected to be a useful tool in further development work to initiate and structure a dialogue among the personnel, especially focusing the design of the future work organization in the CSCW system.

\section{A Case Study of the Test of the ELAKT Prototype}

The methodological approach of the empirical work was a qualitative case study (Merriam 1994). Several personal visits to the organization at different stages of the test work were made. Qualitative interviews were conducted with the main actors (system developer, project leader, the staff at the local office that was testing the prototype). The interviews with the test personnel were conducted as group interviews with two or three informants. The interview situation then became more socially dynamic when compared to traditional interviews with one informant. According to Kvale (1997), the interview then also becomes a learning situation for the participants , allowing different aspects of the issues to be analyzed and discussed. The interviews took about an hour, on average. Most of the interviews were tape-recorded and transcribed verbatim. The researcher also attended one meeting where the test personnel were educated in the ELAKT prototype by the system development personnel. Some written documents have been studied, such as manuals and descriptions of the prototype.

One aim of testing a prototype is to receive the best knowledge possible about the consequences that will arise when the system is introduced for ordinary work. The informants, therefore, were asked what they expected as consequences of using ELAKT in terms of their work situation and quality and efficiency aspects.

The fact that the prototype was tested of the staff of just one local office means that the potential of the technology to change the work organization among different offices was not realized during the test. The test work was done in parallel with the ordinary work, which means that the potential of changing the work organization within the office was not realized. Rather, the informants were asked about expected changes to the work organization, their work situations, and efficiency and quality aspects.

\footnotetext{
${ }^{2} \mathrm{MOA}$ is an acronym derived from the title of the author's dissertation: Människa, Organisation, $A D B$ system (Human Being, Organization, EDP-system) (Grundén 1992).
} 


\section{The Development of the ELAKT Prototype}

The ELAKT prototype system consists of a relation database in Sybase with a graphical user interface in Visual Basic. The relation database is used for keeping track of current matters. Statistics can also be produced from this database. The relation database is connected to Lotus Notes, which is used as a document database. The documents are stored in Lotus Notes. Information from the relation database can be mirrored and presented in Lotus Notes. A root document is created for every person with a current or completed pension matter. All information needed for handling pension matters can be stored electronically in the ELAKT prototype.

The development of the ELAKT prototype was part of a Lotus Notes project initiated by the National Social Insurance Board (in Swedish Riksförsäkringsverket, RFV) in the spring of 1996. Five different regional social insurance offices took part in the project. The ELAKT system was the only system developed for dealing with pension matters. The most common applications of Lotus Notes were conference systems and discussion databases. Another common application was a reference database that stored formalized information such as manuals or law sections. Lotus Notes was also used as an intranet system in order to distribute internal information. One office also tested using Lotus Notes to facilitate distance work. In August 1997, the final report was published with some evaluation of the different applications. Some of the experiences with Lotus Notes were very positive. Lotus Notes was seen as one solution to attain simplicity, security, accessibility, and a comprehensive view within the field of social insurance work. The report also references other positive experiences with Lotus Notes in Swedish public administration, such as the administration office of the Swedish Parliament and the national tax department. Some general negative experiences were, however, distinguished. The project was just a test and those involved felt the future use of the system to be very insecure, a fact that reduced their enthusiasm. The project also had low priority from the central level and from the central EDP department at Sundsvall. According to the final report from RFT, the following consequences were epxected from the ELAKT system:

- A complete and always available electronic record for each social pension matter in which the documents could be viewed in chronological order.

- Work methods would be more flexible, and not limited by geographical or organizational boundaries.

- Other personnel would be able to attain information about the status of the matter and the responsible person for each social insurance matter more easily than was currently possible.

- Security was expected to increase, as different people could receive different authorities.

The evaluation was, however, not based on real tests of the system.

A regional system development department of Bohuslän (RSDD) developed the ELAKT prototype. RSDD had at that time about six systems developers to give support and education regarding IT issues to about 15 local offices. RSDD also worked with systems development of information systems. RSDD employees worked very closely with the users. They characterized their style of systems development work as an organic style. 
The systems development work was seen as very important for the employees of RSDD. They wanted to improve their special competence in the field while developing efficient systems for the organization. The development of the ELAKT prototype was an important project for them. The system development work was part of the central project SIB 2005, but the future of the ELAKT prototype was very insecure and there were simultaneous efforts from the central level to develop other similar systems. In fact, the test work of the ELAKT prototype was interrupted in the middle of 1999. Decisions were made by the central level of management to develop another similar system using different software. This group had shown very little interest in the development work of the ELAKT prototype. But the manager of the RSDD group had been very positive about the development and struggled to have the prototype accepted. Even if the ELAKT prototype would not be used in ordinary work, the development and test work was seen as valuable. The development and test of the prototype increased knowledge about the technology and about new ways of organizing work when dealing electronically with social insurance matters. Resumed testing of the ELAKT prototype, especially focusing on work organization aspects, is planned for the beginning of 2000 with another local office being added to the project. A real test of different distributions of work tasks among two offices would then be possible.

\section{The Planned Future Work Process Compared with the Work Process Today}

Today, work processes for dealing with pension matters are initiated by an application for social pension from the client. Most of the local offices have separated further dealings into two different departments. The investigation department does the necessary investigative work. Contacts can be made with consultants or medical doctors. When the investigative work is finished and a final decision is proposed, the matter is transmitted to the person that will report on the case to the social insurance committee. A date for the meeting is booked. The personnel at the pension department are informed about the matter and start the accounting work. This work is completed when the final decision in the social insurance committee is made. If the proposal from the investigation department is allowed, information about the conclusions in the matter is submitted to the central information system in Sundsvall and the pension is paid to the client. If the claim is denied, the client cam make a new proposal, after a specified time; a new matter is initiated and a similar work process takes place.

Today all documents needed for handling pensions are paper documents. The documents are physically stored in an archive. When external actors such as consultants or medical doctors need information about the document, a copy must be made and sent through the post. The person currently responsible for the matter stores the documents. When the work is transmitted from the investigation department to the pension department, the documents are physically transferred to the new person responsible.

The overall functions of the current work process are similar to the work functions of electronically handling pension matters. When the local office receives an application for social pension, certain information about the client is registered in the relation database and a root document, as well as a mirror document, is created. It is also possible to create specific documents that belong to the pension matter. Documents can be 
scanned into the electronic document, transmitted as a Word, Excel, or Jetform document, or directly written into the database. All information that had been stored in a paper journal can now be stored electronically. ${ }^{3}$

All further dealings are then registered in the ELAKT system. The investigation department initially deals with the matter. When they have finished, the matter is transmitted to the person that will report on the case to the social insurance committee. That person transmits the authority to the pension department for further dealings with the matter in ELAKT after the date for the meeting is noted. The investigation and the pension departments can then deal with the matter in parallel until the final decision is made. The person responsible for the matter can delegate authorization to read the whole electronic journal or part of it to consultants/advisors, deputies, or the insurance doctor. Even the switchboard operator could be authorised to read some elementary information of the journal.

The main changes have more to do with work organization and methods than functions. The information about the matter is registered, stored, retrieved, and transmitted electronically instead of by paper documents. This implies a potential for future organizational changes that could lead to consequences for the individual regarding work content and quality and efficiency aspects.

\subsection{Initiation of the Test Work}

The ELAKT prototype was demonstrated for several participants from different local offices in the region of Bohuslän during the spring of 1997. Several offices expressed interest in participating in the test. The main advantage of the ELAKT system was interpreted by the participants as being a way to keep the pension documents in better order than was currently possible. The system also seemed to reduce the need of sending documents by post to the different actors handling the pension claim. It would also be easier for actors at different geographical locations to look at the same document in ELAKT.

The local office in Kungälv was chosen as a test office by the project management for several reasons. The office was situated very near the system development office. The cooperation among the staff was positive and they, as well as their manager, were interested in technical issues. One of the staff members was a system administrator of the pension system. The test work of ELAKT started in the spring of 1998. About four people at the local office in Kungälv took part in the test work in the beginning. They were from the department of.investigation work and the department of pension handling. They attended two days of education in the ELAKT system.

\subsection{Experiences of the Test Work}

The test of the prototype was done in parallel with the ordinary work. Some of the pension matters were administered manually as well as being registered in the ELAKT

\footnotetext{
${ }^{3}$ According to current law, decisions still need to be stored as a paper document.
} 
system. Some of the documents were scanned into the ELAKT system. The test personnel tried to do most of the test work during times when the ordinary workload was lighter. According to the interviews, the test personnel were very enthusiastic and positive about the ELAKT system. The test work was causing them more work than just handling the pension matters in the ordinary way, but they thought it was very interesting to be able to take an active part of the development of the system. They were aware of the fact that another system might be chosen for the future work, but they did not see this as a big problem. Instead they thought they learned a lot from the test work and it allowed them to try a quite different way of doing their work, a way that they thought would be a model for their future work.

There have been some technical problems, such as too a long response time. There also have been some problems with the scanner, but most of the problems seem to have been solved by the system developers.

The work organization of the local office has not been changed due to the test work, but the individual work situation for the test personnel has changed. They have to do more work than before. They have increased their knowledge about how to handle pension matters electronically.

The test personnel receive system support primarily from one of the system developers, who seems to be very enthusiastic and engaged in the work. He is continually in contact with the test personnel by phone. They can ask questions of more general technical character using a discussion database in Lotus Notes.

In order to follow the test work and discuss any changes of the system, meetings are held with the system developers, the project leader and the test personnel. These meetings have not been as frequent as is usual in development work primarily because of the frequently used discussion database and the ELAKT database. Using the ELAKT database, the system developer and the test person can look at the same document at the same time. According to one of the system developers, the uncertain future of the ELAKT system due to the decision being made in the central part of the organization has affected the speed of the development of new functions and changes to the system.

\section{Expected Consequences of Using ELAKT in Ordinary Work}

\subsection{Consequences for the Organization of Work}

All of the informants think that the distribution of pension matters could be more flexible among the different organizational units as well as among the social insurance staff. You don't have to move the physical documents; you just change the authority. The workload for one office with a shortage of personnel capacity at a given time (e.g., due to vacancies or illness) could then be reduced and some pension matters be moved to another office. The system could produce current statistics of the workload of each office (and each of the pension handlers) which could be used for decisions about changing the distribution of the matters.

The use of consultants, advisors, and medical doctors could also be more flexible, according to the informants, as they could be given the authority to read special insurance 
matters in the ELAKT system and discuss the matter by phone with the person responsible. One of the system developers expects the work to be more specialized than today, both on the office level and on the individual level. The competence of the staff will then be used in a more effective way.

\subsection{Consequences for Individual Work Content}

The test personnel are somewhat worried about the fact that some personal contacts could be reduced or replaced with electronic communication. The social interaction among specialists and the handlers of the insurance matter could be reduced, as most of the information about the client is stored in the electronic system. Meetings could be reduced and important information of a more informal character could be lost, which could affect the quality of the decisions that are made.

One of the system developers expects future work to be more specialized for personnel dealing with complicated social insurance matters. If the work becomes more specialized, the formal work group could be spread around several offices, which could affect the personal contacts among the group members. The personnel dealing with less complicated insurance matters that can be completed during a client visit could be generalists.

One of the system developers expects the work with electronically handling social matters to be more formalized and controlled. There could be controls in the programs of the contents of the documents indicating that specific documents are needed. It will also be easier for managers to receive information about the number of matters being handled by each employee.

All of the informants think that more technical knowledge will be needed in the future work.

\subsection{Expected Consequences for Quality and Efficiency Aspects}

Changes to the organization of work and individual work content also can affect quality and efficiency aspects. Will there be any change to the quality aspects, such as the contents of the decisions that are made or integrity and security aspects, due to the use of this CSCW technology? If consultants and experts could be contacted more easily, the quality of the decisions that are made in the handling of social insurance matters could be increased. But if important informal information is lost due to less personal meetings, then the quality of the decisions could deteriorate.

Most of the informants expect that electronically dealing with pension matters will be safer than today. One of the test personnel compares the security aspects of electronically dealing with pension matters to electronically dealing with patient journals at hospitals. The authorization could be much more restrictive with pension handling, as fewer personnel need to have information about the contents of the matter, as compared with the journal of a patient.

Will the efficiency aspects, such as the time needed for each pension matter or the division of work among the workers, change when the pension matters are handled 
electronically? The test personnel expect the time for handling a pension matter to be reduced. Currently, much time is spent searching for documents that have "disappeared." There will be much less paper in the archives. They also think the system will reduce the need to make copies of documents and send them to external actors such as experts when handling a pension matter. Using the ELAKT system, the actors could instead look at the same document at the same time. When a client makes a demand for a copy, the information could be printed from the system rather than having to make a copy of each document. But the test personnel think that the paperless office is a myth. It is easier to read a paper copy than to read on the screen. There could also be a feeling of security in having the information on a paper document. It is easier to bring a paper copy if you are going to discuss with a colleague.

\section{New Design Methods for Developing CSCW Systems Needed}

The traditional life cycle model for system development work is not as relevant for the development of CSCW systems. Traditional system development work has a more rigid character; most of the detailed specifications of the system are done in the early stages of the process. The focus is mainly on the technical aspects of the system. Supporting cooperation and coordination with information technology shows characteristics that differ from traditional information systems (Grudin 1994; Kyng 1991). There is thus a need for a revision of traditional system development strategies; a new tradition of methods for CSCW is emerging. Still, this tradition is very immature. Very often this tradition uses disciplines such as sociology and ethnography as a means for understanding the social interaction in the work.

A pilot implementation could be a successful method for video communication, as shown by Grundén (1997). For more complex CSCW systems with more programming work, prototyping as a system development method could be a relevant approach for the development process. The specification and test of a prototype is a kind of experimental situation. It is easy to make changes to a prototype. The test of a prototype in real settings could generate experiences with the potential for future alternative ways of using the technology, for example, different ways of organizing work using CSCW technology. The test of a prototype could be seen as a learning process to generate knowledge about future design of the work organization. It is important to integrate such experience from the test work into the system development process. Such work could be systemized in different ways. The experience from the test work about future design alternatives for the work organization could be communicated during special meetings between the system development personnel, the test personnel, and other important actors.

Scenario is a commonly used method for future planning situations and has its background in military war games. Scenarios could be described as future histories, descriptive narratives of possible alternatives that need to be plausible, credible, and relevant (Fahey and Randall 1998). Within a modern, flexible organization, there is a need to identify, discuss, and evaluate many different strategies and their consequences. Scenarios could be used as a design method in order to identify, discuss, and evaluate future possible organizational and technological alternatives (both formal and informal 
in character) and their consequences for the individual work situation and efficiency and quality aspects. Scenarios contrast with traditional functional analysis and specifications. The use of scenarios could raise more questions in the discussions than they settle, but they could also be used as a method for supporting new thinking about design. Systems design could be seen as designing scenarios of interaction (Carroll 1995). The use of scenarios could facilitate strategic conversations that could contribute to continuous organizational learning (Schwartz 1998). Special qualities of the method are the contribution to a higher level of group understanding and qualitative causal thinking (van der Heijden 1996). Bardram (1996) uses scenarios as a technique within the strategy of organizational prototyping to enable discussions of different ways of organizing the organization and the technology. Another similar method is organizational games (Ehn and Sjögren 1991), but this method only focuses on organizational issues.

\section{The MOA-S Scenario Model}

The design of the technology and work organization can affect the work contents and efficiency and quality aspects. Grundén (1992) introduces a human-oriented perspective of an organization that emphasizes important relationships among ideas about coordination and control, the design of the EDP system, and the organization and possibilities for individual development in the work situation. In Figure 1, quality and efficiency aspects are added to the perspective.

The relationships between the boxes of the figure are very complex as changes of work often generate political processes with power struggles among the actors. The model could be used as an evaluation model of technology and/or organizational changes or a scenario model for describing possible outcomes of coming changes.

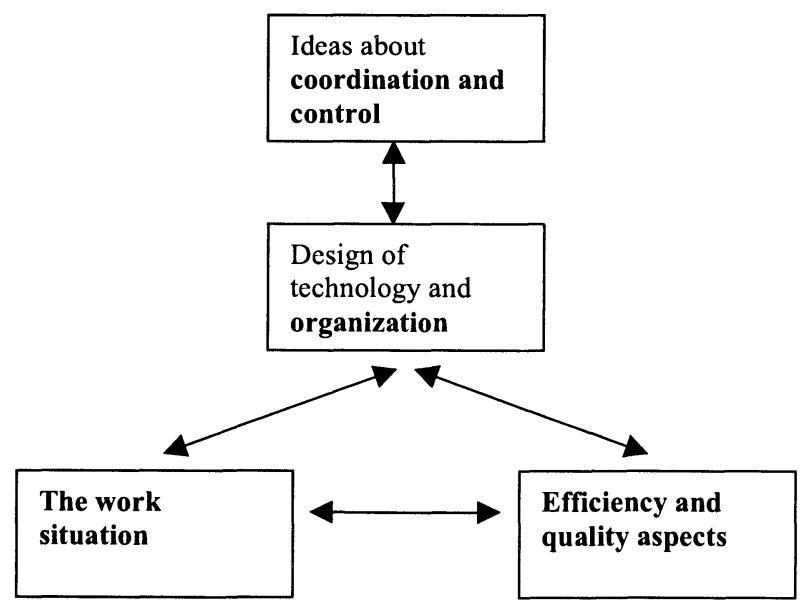

Figure 1. The MOA-S Model 


\subsection{Design of Technology and Organization}

Both the designs of the organization and the CSCW technology can be influenced by ideas of the management regarding control and cooperation aspects. As Leifer (1988) describes, a bureaucratic and hierarchically structured organization, has more complex, centralized computer systems than a more decentralized organization, which as has a more decentralized computer system. In the terminology of Mintzberg (1984), the administration of the Swedish Social Insurance Board could be described as a combination of a machine bureaucracy and a professional bureaucracy with mainly centralized computer systems. As the CSCW technology has the potential of supporting very flexible and also informal communications for an organization, it is an interesting future research issue to investigate to what extent this potential will be realized in the social insurance board.

\subsection{The Work Situation}

Some important aspects of individual work content can be influenced by changing the organization or the information system (Grundén 1992). The implementation or change of information systems very often changes the patterns of social interaction and cooperation of the organization. The contacts between personnel can be reduced or increased. Change of media for communication can affect the quality of the communication. Face-to-face communication includes more informal information than does mail communication. Different communication media also require different coordination mechanisms. Dealing with pension matters using CSCW technology can change the nature of communication and coordination mechanisms among the actors.

The autonomy of the work is one of the most important aspects (Gardell 1986) that also could be affected. According to traditional Taylorism, the human being is seen more or less as a machine and an object for control. Other organization theories emphasize to greater extent the importance of human values. In a professional bureaucracy or in an "adhocracy" (Mintzberg 1984), the workers have more influence on their work situation, based on their professional knowledge, compared with a machine bureaucracy. The CSCW technology can be used in order to increase or decrease the control of the work, depending on the design of the system.

The workers' knowledge of the work could also be changed when new technology is used. When a big information system was implemented in the Swedish social insurance organization during the 1980 s, the knowledge of the personnel became more formalized, abstract, and computer oriented. Some of the old knowledge of the workers of the insurance system has been lost (Josefsson 1985).

When an information system is introduced, the time for dealing with a matter very often is reduced. More matters can be dealt with, within a shorter time period than before. The workload for the individual is then increased, which could result in a work situation that is more stressful and less varied than before. If the work situation instead is organized so that other work tasks can be substituted, the variation will increase. 


\subsection{Efficiency and Quality Aspects}

There is a strong pressure on the public sector to make the work as efficient as possible and produce services with high quality. Efficiency can be defined as the amount of utility or goal fulfilment that is reached compared with other resources. One aspect of efficiency is productivity: the volume of the production compared with the used time or salary costs. A study by Johansson and Ulfvensjö (1990) shows that efficiency was the motive for most of the organizational changes within the Swedish local government sector. This is similar to the efforts within the Swedish Social Insurance Board.

The use of CSCW could contribute to increased efficiency if the time for dealing with pension matters could be reduced. If more contacts with actors at different geographical locations could be done using the electronic database, then time for distribution of paper documents could be reduced. If the time for dealing with a pension matter is reduced, the client has received a better quality of service. The quality of the decision making regarding the pension matter could also be affected if the information is stored in an electronic database. The availability of the information could be better when the information is stored electronically and the programs could execute more controls on the information. Other quality aspects, such as integrity and security, could also be affected when CSCW technology is used.

\subsection{The Notion of Work Organization}

The concept of work organization has changed over time and among different researchers (Macheridis 1997). According to Mintzberg, organizational structure can be defined as the way of coordination and distribution of work tasks in an organization. Organizational structure could be more or less consciously planned. In organizational theory, a general distinction is between the formal and the informal organization. According to a classical definition by Litterer (1963, p. 10), the formal aspects of an organization are aspects that are consciously planned. One example of the formal organization is an organizational scheme. The informal aspects are conceived of as the aspects of organization that are not formally planned but more of less spontaneously evolve from the needs of people.

One example of the informal aspects is informal social networks in the organization. An institution, as defined by Berger and Luckman (1989), can be characterized as a combination of formal and informal aspects. An institution of the organization is manifested when patterns of actions become a habit among several actors. ${ }^{4}$ Such patterns of actions could serve as norms that control the human behavior of the organization. According to Grundén (1992), the EDP system could be conceived as an institution of the organization. As an institution evolves as a combination of formal and informal aspects, there are more organizational alternatives and organizational choices compared with the use of more traditional technology. Each organizational choice has a different implication for the work situation of the individual and for the efficiency and quality aspects. However, it is more difficult to specify such new patterns of communication in advance

\footnotetext{
${ }^{4}$ Conventions, as described by Mark, Fuchs, and Sohlenkamp (1997), could be treated as one aspect of institutions.
} 
compared with the use of traditional information technology. The CSCW technology is often used in more informal settings and facilitates more informal communication compared with the old technology (Kraut et al. 1993). When CSCW technology is introduced in an organization, drifting of the use is a common phenomenon (Ciborra 1996).

\section{The MOA-S Scenario Model for Integrating Work Organization Aspects into the Design Process of CSCW Systems}

The results from the case study show that the test work has generated experiences and knowledge about possible ways of using the system in future work. These experiences need to be systemized and integrated into the development process in order to enable the articulation and design of the future organization. Several discussions and decisions about the future design (both formal and informal aspects) of the work organization when the CSCW technology is used need to be made before electronically dealing with pension matters can be fully integrated in the ordinary work. Scenario is a technique that could be used for such a discussion. The MOA-S could be used as a model specifying different scenarios, such as aspects of the design for distribution of work tasks, control and coordination, social interaction and cooperation, and the paperless office.

Below, different possible scenarios regarding different design alternatives of technology and organization are discussed and some of the consequences of different alternatives, are analyzed using the MOA-S model as a frame of reference. Such a discussion could be integrated into the design process in order to facilitate the future design of the technology and the organization. Such work then needs to be evaluated in order to analyze the relevance of the scenario model for the design work of CSCW systems.

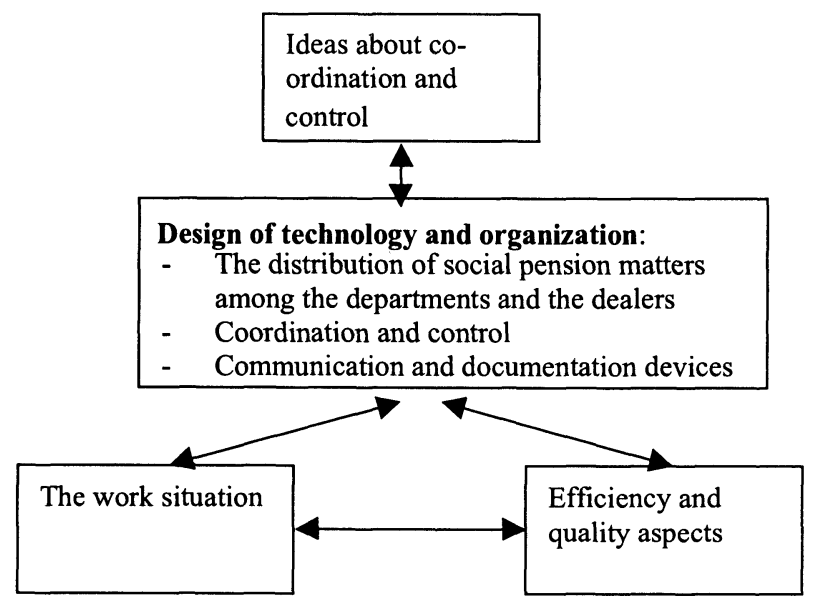

Figure 2. The MOA-S Model as a Scenario Model for Electronic Pension Handling 


\subsection{Distribution of Social Pension Matters Among Departments and Handlers}

The use of electronically dealing with pension matters will require decisions about the actual distribution of pension matters among different offices, departments, and individuals. The potential of distributing the pension matters in a more flexible way among different parts of the social insurance organization will not be realized until several offices use the system.

This will require a change in the work organization. One way is to gather the specialists within a field in one office and distribute all matters in a field to that office. Alternatively, the specialists could be distributed to many offices. The CSCW technology could also be used for communication and cooperation with consultants and doctors at different geographical locations.

The consequence for the work situation is that the stress of a too heavy workload could be reduced, which could improve the work situation of the individuals. This could then be a way of using the staff more efficiently, as the workload could be held more constant. This way of distributing the matters in a more flexible way will probably also require a change in the organizational culture toward a more cooperative and wholenessoriented attitude. Otherwise there could be struggles among organizational units and among the staff. Important issues to solve are deciding the personnel that will participate in decision making about the distribution of pension matters and the criteria to be used in making the decisions (e.g., statistics about current workload).

The individual work content could be more specialized for personnel dealing with more complicated matters. If the specialists in a field are gathered in one office, the personal contacts with the clients would probably be reduced, which could affect the quality of service. Alternatively, the specialists could be distributed to many offices. Contacts with the members of the work group could be made using the CSCW technology, but the personal meetings will probably be reduced.

\subsection{Coordination and Control}

By monitoring the number of matters and the way they are executed. CSCW technology makes it possible to control work more thoroughly than is possible today. One control aspect is the authorization of personnel to read, change, and write into the electronic documents. The authorization to access electronic documents could be made more restrictive than today. Coordination mechanisms could also be changed when electronically dealing with pension matters. The control of the coordination of authorization could increase if the transfer of authorization from one handler to another is given by the electronic system according to programmed rules instead of the more information communication currently in use.

Another aspect of control is the degree of formalization and standardization of the work (Grundén 1992). The work could be more formalized and standardized when using the electronic database when compared with working with paper documents. There could be controls in the program specifying what kinds of documents should be included as well 
as the contents of the documents. Statistics could also be produced regarding the number of matters for each office, department, and individual.

The consequence for the work situation is that the authorization will be more restrictive, which could lead to improvement of such quality aspects as integrity and security. But this is not only a technical matter: it is also a social and cultural matter. A social culture that prevents misuse of authorizations will be needed (Huff and Finholt 1994).

The degree of formalization of the work can affect quality aspects of the service and the individual work situation. There could be advantages to a high degree of formalization in dealing with the matters because of the fact that all clients should have as equal and comparable treatment as possible. On the other hand, a high degree of formalization could lead to a more rigid treatment of matters that do not fit the rules in the programs and individual adjustments are more difficult.

If formalization in dealing with matters will be affected, then the work situation and the knowledge of the individuals also would be changed. The more of knowledge of insurance rules programmed into the software, the less the person handling matter needs to keep in mind, which in turn can affect the learning possibilities and autonomy of the work situation. Technical knowledge would seem to be more important in future work, a fact that could reinforce a tendency of more formalization and standardization of the work. That was one consequence of the early stages of computerization within the social insurance organization studied by Josefsson.

\subsection{Communication and Documentation Devices}

When CSCW technology is used in the work, the communication devices between the personnel could be changed. Different communication devices could affect the quality of communications and the efficiency of professional performance. Different ways of communicating are face-to-face interaction or human-computer interaction.

The future use of electronic systems could reduce the amount of paper documents produced and distributed around the system. A reduction in the amount of paper documents also would reduce the manual work of storing paper documents and keeping them in order, which could increase the efficiency of the work. Documents stored in the electronic system also could be more available as they probably are easier to retrieve than paper documents stored in an archive. ${ }^{5}$ The vision of the paperless office was formulated decades ago, but many offices still seem to have a lot of paper documents (Hedberg et al. 1986).

The consequence for the work situation is that face-to-face interaction involves more informal information than, for example, e-mail interaction. The choice of suitable methods of social interaction and cooperation must be made so that important information is not lost because of it. Even if there are technological facilities that enable communication regardless of time and space, there probably also will be a need for personal meetings because of the quality aspects of the communication. The result from the interviews indicates that informal communication is important in the current work process.

\footnotetext{
${ }^{5}$ There could, of course, be a risk in the electronic system that documents are registered and stored in the wrong document due to human failures, but there probably will be programmed controls to prevent this situation.
} 
To what extent will the theoretical potential of the paperless office be realized in practice when pension matters are dealt with electronically? This aspect of the design has very much to do with informal ways for people to interact with the electronic system. Different people have different individual habits requiring the production of paper documents. Some people prefer to read information from a paper document instead of from a computer screen, especially when the information is discussed in personal meetings. The actual number of hours per day working with a computer terminal is also important. Health problems such as muscle pains or eye stress could be a consequence of working too many continuous hours in front of the computer screen. The actual security and availability of the future electronic system could also affect confidence in the system and the number of paper document produced.

\section{Introduction of the Social Insurance Board to the MOA-S Model}

The MOA-S model as a scenario model for integrating work organization aspects in to the design process was introduced and discussed at a three hours seminar at the Social Insurance Board in September 1999. The model was presented as a frame of reference for discussing different design alternative of the technology and organization of the electronic pension handling as described in the previous section.

Participants at the seminar were systems developers from the whole region of Västra Götaland. In 1999, a significant organizational change of regions in Sweden caused the earlier region of Bohuslän to become part of the new region Västra Götaland. All systems developers with the Social Insurance Board of Västra Götaland are now situated in an office at Gothenburg. One of the people interviewed at the local office of Kungälv also participated.

The presentation seemed to be relevant for the participants and generated a lively discussion. The manager of the systems analysts mentioned that the presentation had raised many new and important issues, especially regarding the design of the future organization of the work and that they were interested in further cooperation in the development work process. So far, the systems analysts had mainly focused on the technical aspects of the system. A central issue of the design of CSCW systems is which parts of the design of the organization systems developers should be involved with and which parts should be left to the users of the systems. Traditionally, most of the organizational aspects are left to the users. However, it is important that there be a dialogue between the users and the systems analysts about organizational aspects of the systems at different stages of the development process. The MOA-S model could be used as a development tool for initiating and promoting such discussion.

\section{Future Work Planned for the MOA-S Model}

In the beginning of 2000, a test of the ELAKT prototype is planned with the Kingälv office and an additional local office. It will then be possible to test and discuss different distributions of the work tasks among the two offices. The use of the MOA-S model will 
be tested in order to support that work and to evaluate and further develop the model and the integration with the systems development process. The model will be presented and discussed both with the systems developers and the users of the systems in order to support a dialogue about the design of the work organization and the consequences for efficiency and quality aspects as well as the work situation.

\section{Conclusion}

The study shows that there are important discussions and choices regarding the work organization that need to be made during the development process. Due to the flexible character of the CSCW technology, more organizational alternatives of the design of the work organization can be taken into account than with the use of more traditional technology, especially regarding the distribution of work tasks, control and coordination aspects, social interaction and cooperation, and communication and documentation devices. There is a need for coordination between the design of the technology and the organization and to integrate such decision-making into the development and implementation process. Different designs of the technology and organization could lead to different consequences for the work situation of the individual and efficiency and quality aspects. There is a need to integrate a discussion and analysis of these aspects into the design process. The scenario model MOA-S is expected to be used as a method for articulating, structuring, and integrating such discussions into the design process. In order to contribute to the development of relevant models for the design of CSCW systems and organizations, further research work is planned in order to test and evaluate the use of such scenarios in real contexts.

\section{References}

Andersen, N. B., and Chatfield, A. "Using IT for Creating the $21^{\text {st }}$ Century Organization.," keynote presentation, Giga's European Business Process and Workflow Conference, Amsterdam, October 28-30, 1996.

Argyris, C., and Schön, D. Organizational Learning II. Reading, MA: Addison Wesley, 1996. Ashkenas, R. Den gränslösa organisationen (The Boundaryless Organization). Lund, Sweden: Studentlitteratur, 1997.

Bannon, L., and Schmidt, K. "CSCW: An Initial Exploration," Scandinavian Journal of Information Systems (5), 1995, pp. 3-24.

Bardram, J. E. "Organizational Prototyping: Adopting CSCW Applications in Organizations," Scandinavian Journal of Information Systems (8:1), 1996, pp. 69-88.

Berger, P., and Luckman, T. The Social Construction of Reality. New York: Anchor Books, 1989.

Ciborra. C. (ed.). Groupware and Teamwork. Chichester: John Wiley \& Sons, 1996.

Carroll, J. M. Scenario-based Design: Envisioning Work and Technology in Systems Development. Chichester: John Wiley \& Sons, Inc., 1995.

Ehn, P., and Sjögren, D. "From System Description to Scripts for Documentation," in Design at Work: Cooperative Design of Computer Systems, J. Greenbaum and M. Kyng (eds.). . Hillsdale, NJ: Lawrence Erlbaum Associates, Inc., 1991. 
Fahey, L., and Randall, R. M. Learning from the Future: Competitive Foresight Scenarios. New York: John Wiley \& Sons, Inc., 1998.

Försäkringskassan. Förteckning över planerade projekt $i$ Utvecklingsprogrammet (A List of Planned Projects in the Development Program), internal report, 1998.

Gardell, B. Arbetets organization och människans natur (The Organization of Work and the Nature of Human Beings). Stockholm: Arbetsmiljöfonden, 1986.

Grudin, J. "Groupware and Social Dynamics: Eight Challenges for Developers," Commications of the ACM (37), 1994, pp. 93-105.

Grundén, K. Människa, organisation, ADB-system. Ett människoorienterat perspektiv på systemutveckling (Human Beings, Organizations, EDP Systems: A Human-Oriented Perspective on Systems Development), doctoral dissertation, Department of Sociology, University of Gothenburg (monograph no. 47). Lund, Sweden: Studentlitteratur, 1992.

Grundén, K. "Local Initiatives with Pilot Implementation of Desktop Video Communication in the Swedish Social Insurance Board," in NOKOBIT-97: Norsk konferense om organisasjoners bruk av IT (A Norwegian Conference About Organizations Use of IT), N. M. Nielsen (ed.), Department of Economy, (Informatics), University of Bodö, June 12-13 1997.

Hedberg, B., Elling, M., Jönsson, S., Köhler, H., Mehlmann, M., Parmsund, M., and Werngren, C. (eds.). Kejsarens nya kontor. Fallstudier om datorisering på kontor (The Emperor's New Office: Case Studies of Computerization). Stockholm: Liber, 1986.

Huff, C., and Finholt, T. Social Issues in Computing: Putting Computing in Its Place. New York: McGraw-Hill Series in Computer Science, 1994.

Jälmestål, C., Sköld, L., and Wahlqvist. "Projektrapport strategier för kompetensförsörjning," delprojekt 1 och 2, Försäkringskassan 980929. Internal report;not published.

Johansson, A., and Ulfvensjö, L. Kommunalt organisationstänkande: en förstudie av kommunernas förändringsarbete under 1980-talet. Örebro, Sweden: Högskolan i Örebro, 1990.

Josefsson, I. "Kampen om innebörden i begreppen" (The Struggle About the Meaning of the Concepts), Språk och erfarenhet. (Language and Experience), I. Josefsson (ed.). Stockholm: Carlsson \& Jönsson, 1985.

Kraut, R. E., Fish, R. S., Root, R. W., and Chalfonte, B. L. "Communication in Organizations: Form, Function and Technology," Readings in Groupware and Computer-Supported Cooperative Work: Assisting Human-human Collaboration,” R. M. Baecker (ed.). San Mateo, CA: Morgan Kaufmann Publishers Inc, 1993.

Kvale, S. Den kvalitativa forskningsintervjun (The Qualitative Research Interview). Lund, Sweden: Studentlitteratur, 1997.

Kyng, M. "Design for Cooperation: Cooperating in Design," Communications of the ACM (34:12), 1991, pp. 65-73

Leifer, R. "Matching Computer-based Information Systems with Organization Structure," MIS Quarterly, March 1988.

Litterer, J. A. Organizations: Structure and Behavior (Volume 1). New York: John Wiley, 1963.

Macheridis, N. Arbetsorganisation. En historisk granskning avkonventioner (Work Organization: A Historical Examination of Conventions), Working Paper, Institute of Economic Research, School of Economics and Management, Lund University, 1997.

Mark, G., Fuchs, L., and Sohlenkamp, M. "Supporting Groupware Conventions through Contextual Awareness," in Proceedings of the Fifth European Conference on Computer Supported Cooperative Work, J. A. Hughes, W. Printz, T. Rodden, and K. Schmidt (eds.). Dordrecht, Netherlands: Kluwer Academic Publishers, 1997.

Merriam, S. H. Fallstudien som forskningsmetod. (The Case Study as Research Method). Lund, Sweden: Studentlitteratur, 1994.

Mintzberg, H. Structures in Fives: Designing Effective Organizations. Englewood Cliffs, NJ: Prentice-Hall, 1984. 
NUTEK. Towards Flexible Organizations. Stockholm: Swedish National Board for Industrial and Technical Development (B 1996:6), 1996.

Schwartz, P. The Art of the Long View Planning for the Future in an Uncertain World. New York: John Wiley and Sons, 1998.

van der Heijden, K. Scenarios, Strategies and the Strategy Process. Nijenrode Research Paper Series No. 1997-01, Centre for Organisational Learning and Change, University of Nijenrode, 1997. (Available at http://www.library.nijenrode.nl/library/publications/nijrrep1997-01/199701.html)

\section{About the Author}

Kerstin Grundén has a background as a system analyst and programmer. She completed her doctorate in 1992 at the Sociological Department of the University of Gothenburg in Sweden. From 1992 until 1995, she worked as a researcher at a center for research about the public sector at the University of Gothenburg. In 1995, she became an assistant professor in informatics at the University of Borås. Since 1997, she has been working as an assistant professor in informatics at the School of Health Sciences at the same university. Kerstin can be reached by e-mail at kerstin.grunden@hb.se. 